\title{
Micropaisagem, 'micro-rigor': em torno da poética de Carlos de Oliveira
}

\author{
Moisés David S. G. Ferreira*
}

\begin{abstract}
Resumo: O presente artigo procura analisar uma das dimensões mais originais e valorizadas da poética de Carlos de Oliveira, nomeadamente a de uma concepção da poesia como "trabalho oficinal". A constante busca de aperfeiçoamento do texto poético, resultando numa reescrita contínua, orienta-se neste poeta português para a obtenção do chamado 'micro-rigor', expressão referente a uma máxima concentração expressiva capaz de dotar o texto de uma maior eficácia e de revitalizar os processos de interpretação e transformação da realidade. Tomando o livro Micropaisagem como paradigma desta poética, tenta-se entender de que modo o conceito de 'micro-rigor' pode fornecer uma chave para uma compreensão global do poema e do acto de criação poética, na proximidade da fenomenologia das experiências místicas.
\end{abstract}

Palavras-chave: Carlos de Oliveira; poética; reescrita; micro-rigor; experiência mística.

\begin{abstract}
The present article seeks to analyse one of the most original and valued dimentions of the poetics of Carlos de Oliveira, namely the one which involves a conception of poetry as the practising of a "craft". The constant search for the improvement of the poetical text, resulting in a continuous rewriting, is oriented in this portuguese poet to the attainment of the so called 'micro-rigour', expression which is refered to a maximal expressive concentration able to give the text a greater efficacy and to revitalize the processes of interpretation and transformation of reality. Taking the book Micropaisagem as paradigm of this poetics, it is tried to understand in which way the concept of 'microrigour' may give a key to a global comprehension of the poem and the act of poetical creation, in the proximity of the phenomenology of mystical experiences.
\end{abstract}

Keywords: Carlos de Oliveira; poetics; rewriting; micro-rigour; mystical experience.

\section{Introdução}

A poesia de Carlos de Oliveira, vinda à luz entre os anos de 1941 e 1976, e em considerável parte objecto de sucessivas reformulações pela mão do autor, encontra-se hoje reunida sob o título Trabalho Poético ${ }^{1}$. Como facilmente se constata pela conjunto de estudos que não cessa de suscitar entre os estudiosos e os críticos da literatura, a obra poética de Carlos de Oliveira continua a despertar, por diversos motivos, um muito marcado interesse. Seja pela integridade e coerência do seu percurso evolutivo, ou pela vivacidade da voz que dela se desprende, profundamente atenta às grandes questões do seu tempo e, em simultâneo, capaz de inscrever-se numa intemporalidade a que poucos corpora literários conseguem guindar-se,

\footnotetext{
* Mestrando em Criações Literárias Contemporâneas pela Universidade de Évora, Portugal; detentor do grau de Licenciatura em Psicologia pela mesma instituição. E-mail: mdsgferreira@gmail.com
} 
seja ainda pela limpidez e perfeição formal que o autor consegue imprimir-lhe, na sequência da assunção de uma agudíssima consciência do processo criativo que terá como resultado uma escrita em que se tornou fácil identificar um traço a que muito justamente foi atribuída a designação de 'rigor poético' (cf. GUSMÃO, 1981, p.77) - e para que o próprio título sob o qual a obra poética é publicada, Trabalho Poético, parece já apontar (cf. RUBIN, 1991, pp.45-53) -, a poesia de Carlos de Oliveira é, segundo cremos, um dos mais originais e brilhantes percursos da poesia portuguesa do séc. XX.

Com o presente artigo pretendemos centrar-nos sobre um dos aspectos que mais interesse nos desperta nesta poesia, nomeadamente a já mencionada questão do rigor poético e dos posicionamentos que Carlos de Oliveira desenvolve em torno do sentido da fabricação da escrita, procurando analisar e interpretar algumas das suas mais evidentes e eloquentes manifestações na poesia do autor, sobretudo no livro Micropaisagem, considerado uma das obras mais radicais do autor e da poesia portuguesa contemporânea (cf. SILVESTRE, 1996, p.82).

\section{O caminho evolutivo da poesia de Carlos de Oliveira}

Manuel Gusmão (1981, pp.23-25), na análise que faz do percurso poético de Carlos de Oliveira, conclui ser possível distinguir duas fases na produção poética do autor, ao longo das quais esta vai sofrendo um nítido desenvolvimento, e cuja apreciação global enriquece as leituras de cada um dos livros vindos a lume. Uma primeira fase compreenderia os livros Turismo (1942), Mãe Pobre (1945), Colheita Perdida (1948), Descida aos Infernos (1949) e Terra de Harmonia e Ave Solar (1950). Neste período, de acordo com Gusmão (1981, p.63), é particularmente notória uma proximidade do cancioneiro popular, bem como de algumas das mais marcantes vozes da poesia portuguesa, desde Camões a Gomes Leal, de Cesário Verde a Fernando Pessoa, ou de Afonso Duarte a Miguel Torga. A proximidade deste património literário irá concretizar-se na adopção de algumas formas de expressão mais características dentro do espectro desse conjunto de referências (e. g., o soneto e o poema longo, de pendor narrativo).

Outro dos aspectos que GUSMÃO (1981, p.64) salienta nesta fase é a assunção da poesia como modo de configurar, ou cimentar, uma relação de profunda solidariedade com os outros seres humanos e as condicionantes da sua situação histórica. A poesia é referida como 'voz’ e ‘canto', ‘canção' e ‘choro', sendo a sua função sobretudo comunicativa e expressiva.

\footnotetext{
${ }^{1}$ Todas as citações da poesia de Carlos de Oliveira apresentadas ao longo deste artigo seguirão a seguinte referência: OLIVEIRA, Carlos de. Trabalho Poético. Lisboa: Círculo de Leitores, 2001a.
} 
Exemplos do que acaba de ser dito, também mencionados por Gusmão, podemos encontrá-los em: "Hei-de cantar-vos a beleza um dia" ("Soneto", in Mãe Pobre); "A minha voz de morte é a voz da luta" (idem); "Cantar / é empurrar o tempo ao encontro das cidades futuras" ("Canto", in Terra de Harmonia). No entanto, para além desta dimensão, esta voz poética acha-se igualmente envolvida num arreigado comprometimento e imersão no tecido da realidade. Testemunho disto é a presença de marcas de oralidade, que se coadunam não apenas com a filiação literária do autor, mas também com um entendimento do poeta enquanto 'intérprete' e 'interlocutor', no âmbito do que se nota a presença das dimensões confessional e narrativa nesta escrita. O poeta, ao dizer, age, fazendo libertar-se da palavra um poder encantatório e transformador.

A tensão gerada no seio desta poesia organiza-se precisamente em torno da problemática da transformação. As dialécticas que surgem oscilam entre a realidade e o desejo de uma realidade nova, a vida e a morte, o desespero e a esperança, concretizando-se na enunciação dos opostos dia/noite, frio/calor, memória/esquecimento (cf. GUSMÃO, 1981, p.66). No entanto, o principal núcleo de opostos encontra-o GUSMÃO (1981, p.66) nos termos sujeito/canto, mundo/matéria e história. Esta é, para o crítico, a relação que está na origem do aparecimento de todas as outras relações, e que introduz a dialéctica do movimento. A voz poética, mergulhando no movimento da natureza e da história, procura dizer-se nesse mesmo movimento, dizê-lo e, ainda, participar nele. É a partir desta problemática que, para GUSMÃO (1981, p.67), Carlos de Oliveira vai ao encontro do que no real é factor de imobilidade e de decadência, buscando, em simultâneo, o que se transforma, o que engendra a esperança.

A poesia deste período constitui, pois, com maior evidência, uma demanda da participação no processo de trabalho e de transformação inerente à aventura do conhecimento (a qual aparece claramente tematizada em A Noite Inquieta, Descida aos Infernos e Ave Solar) em que está envolvido todo o ser humano ao longo da sua vida.

A segunda fase da poesia de Carlos de Oliveira engloba os livros Cantata (1960), Sobre o Lado Esquerdo (1968), Micropaisagem (1968), Entre Duas Memórias (1971) e Pastoral (1977). GUSMÃO (1981, p.67), que considera Cantata um livro de passagem e distingue duas vertentes nesta segunda fase, uma radicada em Micropaisagem e outra em Sobre o Lado Esquerdo, aponta vários elementos caracterizadores da poesia deste conjunto de obras.

Por um lado, o panorama literário de fundo desta poesia não é já o mesmo que se evidenciava na primeira fase. Está agora centrada em referências mais contemporâneas, ainda que Cesário Verde e Fernando Pessoa continuem a ser cruciais. A poesia deste período, ao enveredar por um caminho de extrema depuração - reagindo àquilo a que GUSMÃO (1981, 
p.68) chama "discursivismo lírico, confessional e psicologista" -, procurará uma maior concentração expressiva (e, através disso, segundo cremos, uma amplificação do seu poder transformativo). Nos livros desta fase tal demanda torna-se visível com uma maior preocupação com a organização e a regularidade formal e estilística. Os poemas vão, ao mesmo tempo, aproximar-se e afastar-se do soneto. Aproximar-se dele para alcançarem a tensão extrema que o soneto é capaz de imprimir-lhes, e afastar-se quando forem já capazes de originar em si essa tensão sem terem de adoptar essa forma (cf. GUSMÃO, 1981, p.69). Os poemas longos organizam-se agora com base em segmentos de número semelhante de versos, o que não sucedia com os poemas longos da fase anterior. Esta é mais uma faceta que assume a procura de depuração e de rigor na construção dos textos (cf. GUSMÃO, 1981, p.69). GUSMÃO assinala também que a menor dimensão dos poemas, bem como o seu carácter regular, vão dar origem a uma maior tensão rítmica e expressiva. Outros recursos enumerados pelo autor contribuem também para este efeito, nomeadamente a elipse, a pontuação cortada, a fragmentação, a enumeração substantiva ou a proliferação de verbos activos e de movimento.

Outra das características para que GUSMÃO (1981, p.70) chama a atenção é a diluição das marcas de presença do sujeito de enunciação nos poemas. Assiste-se agora a uma rarefacção da individualidade psicológica. Da poesia como 'voz' e 'canto' passa-se a uma poesia em que é mais vincada a valorização da dimensão da escrita. Na sequência disto, assiste-se à emergência de um discurso metapoético, em que o poema se analisa a si mesmo e reflecte sobre os seus próprios processos. GUSMÃO sublinha justamente que a passagem da valorização das imagens da voz à valorização das imagens da escrita vai significar uma agudização da consciência do trabalho próprio do 'escrever'. Se por um lado as palavras parecem perder o seu poder mágico e encantatório, o poder de, ao serem ditas, mudarem as coisas, por outro lado parecem adquirir uma maior leveza e agilidade. As palavras, mais conscientes da vida própria que em si albergam, buscam agora a imersão nas realidades mais pequenas e mais complexas, querem tornar mais amplo o seu poder de conhecimento e de reconstrução do mundo. Contudo, nunca se perde, com esta espécie de autonomização das palavras, com a sua transformação em artefactos, em objectos de um demorado trabalho, a capacidade referencial, descritiva, das próprias palavras: as palavras, no seu movimento, pretendem testemunhar, com uma cada vez maior acuidade, o movimento do mundo (cf. GUSMÃO, 1981, p.71).

Apesar da nova feição assumida pela poesia desta segunda fase, não fica diminuída a função comunicativa que é possível identificar na primeira fase. GUSMÃO (1981, pp.71-72) detecta nesta poesia uma agudização da consciência da fragilidade das palavras e da resistência do mundo a ser dito (i. e., a tornar-se 'transformável'), sendo que em simultâneo se procu- 
ra, através do labor poético, dizer rigorosamente as coisas. Parece abandonada a crença no poder demiúrgico das palavras, em favor de uma centração no seu valor enquanto meio de conhecimento e enquanto material e produto da poesia.

Nesta segunda fase é ainda evidente uma referência mais insistente ao mundo mineral e mineralizado, ao contrário do que acontecia na fase anterior, cujos poemas se reportavam sobretudo a aspectos do mundo orgânico. Esta referência recorrente ao mundo mineral revela a particularidade de estender aos elementos do mundo orgânico as propriedades do próprio universo mineral, sendo que assistimos a um processo de 'mineralização' desses elementos. GUSMÃO (1981, p.72) olha para este fenómeno de mineralização nalgum do universo poético desta fase (nomeadamente no de Micropaisagem) como um patamar inscrito num movimento mais largo, um estado de paragem que prepara o retomar do movimento, movimento que faz implodir o que se encontra petrificado, imprimindo-lhe a fluidez e a flexibilidade de tudo aquilo que é irredutível a fórmulas ou tentativas de apropriação. Assiste-se, por outro lado, à instauração de uma dialéctica entre o mundo mineral e o mundo cósmico, que de forma semelhante se constroem.

Outro aspecto a sublinhar diz respeito ao maior relevo que toma a oposição imobilidade/movimento e a relação poema/mundo, já presentes na fase anterior, mas nesta fase plenamente assumidos no seu valor de matriz de engendramento da tensão poética. Curiosamente, na medida em que o vocabulário referido ao mundo exterior se acentua, observa-se que aumenta concomitantemente a capacidade de abstracção desta poesia (cf. GUSMÃO, 1981, p.74). De facto, opera-se uma reprodução da realidade concreta pelo conceito abstracto, o que, segundo cremos, intensifica a percepção dessa mesma realidade. A noite do tempo, da história, de cada ser humano e do próprio poeta enquanto caminhante no mundo, "a noite que cercou o meu ofício" (“Soneto Fiel”, in Sobre o Lado Esquerdo), só pode ser vencida pela mão de uma escrita que, aparentemente destituída de fecundidade, uma escrita pobre e rude, mas assim tornada leve, da mesma "leve têmpera do vento" ("Soneto", in Cantata), se torna capaz de ser fiel à complexidade extrema sobre a qual se ergue toda a existência no mundo, transformando-se em instrumento que demorada e meticulosamente restaura aos olhos humanos "o trémulo / fulgor / da vida” (“Aresta”, in Micropaisagem).

\section{0 ofício da poesia e a poética da rarefacção}

Será porventura unânime considerar que a dimensão que mais claramente ressalta da poética de Carlos de Oliveira é a concepção da poesia como trabalho. GUSMÃO (1981), 
RUBIM (1991), SILVESTRE (1996) e CRUZ (1999b) apontam sistematicamente para esse aspecto, que é talvez mais visível nos livros da segunda fase que Gusmão delimita na poesia do autor. CRUZ (1999b, p.70) ousa mesmo afirmar que, em toda a literatura portuguesa do século XX, talvez nenhuma outra obra seja marcada por uma disciplina estilística tão profunda como aquela que tão visivelmente se manifesta em Carlos de Oliveira. Palavras como 'disciplina', 'precisão', 'rigor' são-lhe atribuídas enquanto directrizes do seu trabalho poético, sendo um modo de dar corpo a uma ligação mantida com um 'universo essencial' (cf. CRUZ, 1999b, p.70).

A propósito das concepções subjacentes à sua escrita poética, valerá sobretudo, mais do que o rigor analítico de qualquer estudioso, a eloquência das palavras do próprio Carlos de Oliveira, que em vários momentos da sua obra se debruça sobre os processos em acção no interior da sua própria escrita. Um dos textos mais recorrentemente citados, e do qual apresentaremos apenas alguns excertos, é "Micropaisagem", inserido no livro O Aprendiz de Feiticeiro:

(1) Micropaisagem não é um desses livros súbitos de que fala Eda Olivier, "textos de origem vulcânica, servindo-se do autor como dum simples médium e jorrando torrencialmente, em pouco tempo". Antes pelo contrário: obra lenta, elaborada com todo o vagar na 'alquimia' dos papéis velhos. Quase sem eu dar por isso o livro surgiu-me pronto, é certo, mas levara três anos a construí-lo. Papéis acumulados, experiências para aqui, para ali, vários livros a crescer lado a lado. Coisas reescritas até à saciedade, e por fim a pequenina explosão já entrevista, apenas sonhada. O aproveitamento (o cálculo) da explosão. Dominá-la, encaminhá-la, etc. Raras vezes a poesia me deu qualquer coisa de graça. [...] O resto é trabalho vagaroso. Feito, desfeito, refeito, rarefeito. (OLIVEIRA, 2001b, pp.199-200)

Mas não só a memória. Também o tempo, a elaboração do poema através dos estratos sobrepostos do tempo, com um rigor que simula a reacção química ou um pequeno sistema planetário. Todo esse rigor, toda essa frieza partiram assim do real, do quotidiano. Frieza aparente, julgo eu. O livro, qualquer livro é uma proposta feita à sensibilidade, à inteligência do leitor: são elas que em última análise o escrevem. Quanto mais depurada for a proposta (dentro de certos limites, claro está), maior a sua margem de silêncio, maior a sua inesperada carga explosiva. A proposta, a pequena bomba relógio, é entregue ao leitor. Se a explosão se der ouve-se melhor no silêncio. (OLIVEIRA, 2001b, pp.200-201)

5) O trabalho oficinal é o fulcro sobre que tudo gira. Mesa, papel, caneta, luz eléctrica. E horas sobre horas de paciência, consciência profissional. Para mim este trabalho consiste quase sempre em alcançar um texto muito despojado e deduzido de si mesmo, o que me obriga por vezes a transformá-lo numa meditação sobre o seu próprio desenvolvimento e destino. É o caso da "Micropaisagem". Um texto diante do espelho: vendo-se, pensando-se. (OLIVEIRA, 2001b, pp.201-202)

Outro fragmento que é conveniente citar para melhor compreender a poética de Carlos de Oliveira encontra-se no texto "Coisas Desencadeadas", também d'O Aprendiz de Feiticeiro: 
Sartre diz algures que "o rigor científico reclama em cada um de nós outro rigor mais difícil, que o equilibra: o rigor poético", sublinhando que se trata de duas formas culturais "complementares".

$[\ldots]$

O poema é um objecto de substância especialíssima, com meios de produção adequados, cuja evolução se processa por caminhos muito seus que não admitem, ao que penso, qualquer ruptura na profunda integridade em que fluem. A poesia evolui, experimenta, liberta-se, mas não deixa de ser um produto directo, dilecto, da consciência humana. A verdadeira vanguarda não imita exactamente aquilo que mais precisa de combater, o esquecimento do homem na rápida aridez do mundo, que não advém do progresso mas do seu uso deturpado. Se a poesia é como queria Maiakovsky uma "encomenda social", o que a sociedade pede aos homens de hoje, mesmo que o peça nebulosamente, não anda longe disto: evitar que a tempestade das coisas desencadeadas nos corrompa ou destrua. (OLIVEIRA, 2001b, pp.196-197)

A este propósito, será ainda importante termos em consideração dois outros textos de

Carlos de Oliveira, agora da sua obra poética. O primeiro deles é o que se intitula "Soneto", do livro Cantata:

Rudes e breves as palavras pesam mais do que as lajes ou a vida, tanto, que levantar a torre do meu canto é recriar o mundo pedra a pedra; mina obscura e insondável, quis acender-te o granito das estrelas e nestes versos repetir com elas o milagre das velhas pederneiras; mas as pedras do fogo transformei-as nas lousas cegas, áridas, da morte, o dicionário que me coube em sorte folheei-o ao rumor do sofrimento: ó palavras de ferro, ainda sonho dar-vos a leve têmpera do vento. (OLIVEIRA, 2001a, p.161)

O segundo texto a que nos referimos é "Soneto Fiel", de Sobre o Lado Esquerdo:

Vocábulos de sílica, aspereza,

Chuva nas dunas, tojos, animais

Caçados entre névoas matinais,

A beleza que têm se é beleza.

O trabalho da plaina portuguesa,

As ondas de madeira artesanais

Deixando o seu fulgor nos areais,

A solidão coalhada sobre a mesa.

As sílabas de cedro, de papel,

A espuma vegetal, o selo de água,

Caindo-me nas mãos desde o início.

O abat-jour, o seu luar fiel,

Insinuando sem amor nem mágoa

A noite que cercou o meu ofício.(OLIVEIRA, 2001a, p.205)

Estes textos merecem-nos diversas considerações. Sublinhe-se, antes de mais, a importância dada à passagem do tempo sobre a escrita, à passagem do tempo enquanto crivo da 
própria escrita. As composições, à medida que sobre elas passa o tempo, são constantemente trabalhadas, reescritas, reinventadas até, no sentido de um maior despojamento e depuração. O culminar deste processo é, apagados que ficam os indícios de um sujeito de enunciação “demasiado psicologista" (GUSMÃO, 1981, p.80), a criação de um espaço de sentido cuja característica fundamental será a de uma máxima abertura ao leitor. Este, ao reconhecer no poema não mais que as essenciais e imprescindíveis palavras para ele mesmo erguer o edifício do significado e efeito poéticos, terá, quanto a nós, uma margem mais larga para projectar-se no esqueleto que é o enunciado do poema, e, assim, acrescentar-lhe a carne da sua própria existência e circunstância, dando à luz o corpo poético propriamente dito. Só assim pode o leitor apropriar-se do poema e, fazendo-o parte de si, torná-lo operativo, quer aproximando-se ele mais do poema, quer deixando que o poema se aproxime mais de si. Notoriamente, para Carlos de Oliveira é da interacção entre o poema e o leitor que nasce a verdadeira escrita, a escrita capaz de (indo ao encontro de um dos pontos de vista a partir dos quais Gusmão analisa a poesia oliveiriana) transformar o mundo. Por conseguinte, afigura-se-nos legítimo afirmar que a depuração se encontra ao serviço da eficácia do texto: quanto mais despojado e depurado, mais eficaz se tornará junto do leitor, i. e., mais capaz de conduzi-lo, convertê-lo a um movimento de transformação do mundo, de luta contra aquilo que, na sociedade, em si mesmo e nos outros, sistematicamente tende a diminuir o ser humano e a vida, a fazer a pessoa abdicar de si, alienar-se. Trata-se, pois, em suma, de preparar as pessoas para um incessante combate contra a alienação. O texto 'rarefeito' será aquele que mais poder dará ao leitor, que mais genuinamente o devolverá a si mesmo, que mais intimamente falará ao que é o traço que, em nossa opinião, mais radicalmente o caracteriza: o da pura potencialidade para criar. No horizonte, é o novo que acena, qualquer coisa sempre a tender para uma condição de alteridade.

Este 'rigor poético', esta 'rarefacção' das palavras, para além de serem a característica que mais pode aproximar o poema do leitor no sentido já descrito, são também aquilo que melhor lhe devolve, ou mais vividamente lhe torna acessível, como dissemos, a percepção da extraordinária complexidade inerente ao real, enquanto marca que o torna fundamentalmente irredutível. Mostra-se assim que o real é sempre outro. Este raciocínio faz-nos, no limite, remontar à distinção kantiana entre ‘fenómeno' e 'númeno' (cf. KANT, 2001, pp.84-85 [B 68]; p.265 [A 249]). Reconhecidos os fenómenos enquanto derivações da realidade última, tendencialmente inacessível, das 'coisas-em-si', o ser humano não pode persistir na pretensão de tudo conhecer de forma exacta, dominando-o; deve, antes, porque só isso permanece ao seu alcance, dialogar com o mundo, aproximar-se dele de forma indirecta, recebê-lo, e, através da 
matéria com que o representa - as palavras, primeiramente - tentar uma reprodução dessa derradeira incognoscibilidade, dessa condição misteriosa do real. Nesta acepção, torna-se lícito regressar ao conceito de 'mimese', cuja pertinência se nos afigura indubitável no cenário duma aparentemente paradoxal 'reprodução do irreprodutível'. Com efeito, a expressão que usamos, 'reprodução do irreprodutível', afinal não alberga em si a tensão do paradoxo, porque o que nela está implícito é, exactamente, a reprodução do carácter irreprodutível do que efectivamente alberga em si a propriedade da irreprodutibilidade.

O rigor poético, a rarefacção, características dominantes na poesia de Carlos de Oliveira que têm a virtualidade de facilitar ao leitor a percepção de condição misteriosa do real, parecem encontrar-se em plena consonância, a partir da interpretação que delas fazemos, com o antigo conceito, que mantém estreito parentesco com a mística de Mestre Eckhart, da douta ignorância, particularmente desenvolvido por Nicolau de Cusa (2000). Com este conceito se sublinha o máximo acerto de um saber do não saber. Uma vez que ao ser humano não é dada a possibilidade, por ser finito, de conhecer o infinito, o desmedido, então resta-lhe avançar para esse infinito e desmedido, que o rodeia e está já em si, através de um caminho de analogias (por meio da linguagem e do pensamento), numa aproximação sempre tangencial daquilo que não pode ser dito nem pensado. A douta ignorância conduz ao reconhecimento de uma impossibilidade fundamental de se chegar a uma coincidência entre ser e objecto, sendo todo o conhecimento possível irremediavelmente incompleto. Ora, se se reconhece isto, então inicia-se um caminho que, fazendo uso das representações através das quais se dá o conhecimento, irá na direcção da criação de um silêncio interior ou vazio que esteja totalmente orientado para uma entrega do ser humano, por via daquilo a que poderíamos chamar um nãoconhecimento, ao infinito e desmedido que está em toda a parte. $\mathrm{O}$ uso destas representações seria feito de modo a privá-las das falácias e possibilidades de distorção que na comunicação corrente dão ao sujeito uma certa sensação de omnipotência e omnisciência que o desviam de uma noção exacta da condição extremamente limitada do seu intelecto. Assim, consideramos que a douta ignorância é talvez uma derradeira sabedoria, que pode libertar do pesado fardo das distorções cognitivas e abrir as pessoas a uma clara perspectivação de si mesmas e dos outros e a uma radical aceitação e abertura à alteridade, que é, em rigor, tudo. Quem somos senão outros de nós mesmos, dos outros e do mundo a cada instante?

O estado de não-conhecimento a que nos reportamos culminaria precisamente na percepção do ser humano enquanto potencialidade pura para criar, pois quem, no processo de conhecimento, se desidentificou da pretensão de coincidir com o objecto e dominá-lo, passa a dispor em si da receptividade para usar os dados da experiência do mundo com a finalidade de 
construir com eles formas que dêem testemunho desse carácter de radical alteridade, já sublinhado, que está subjacente a tudo. Estas formas, construídas a partir desse prisma, seriam símbolos perfeitos, porque uniriam em si a sua natureza de símbolos, que desde logo implica que remetam para uma diferença, a uma intenção subjectiva clara de assim se constituírem.

Rigor poético e rarefacção, eis dois predicados de uma possível ciência dos símbolos, ou arte de construção dos símbolos, pois só por esses meios seria viável um caminho em que o sujeito acederia aos símbolos, às representações, para ir ao encontro do que se situa para lá das representações, e não para nelas se fixar. O espírito, deste modo, iria ao encontro da sua própria verdade.

Um dos principais modos através dos quais, na escrita de Carlos de Oliveira, se a dá concretização do traço do 'rigor poético', é a reescrita, já antes mencionada, e a que agora regressamos. Reescrita, reelaboração, reconfiguração do texto inicial. Reescrita, como dissemos, enquanto caminho de depuração. MARTELO (2002, pp.107-120), ao reflectir acerca da problemática da reescrita na obra de Carlos de Oliveira, e reportando-se ao facto de este sucessivamente ter revisto, reformulado, remodelado inúmeros textos depois de já publicados, atribui à figura do 'reescritor' unicamente a vinculação às versões finais dos textos, enquanto que o 'escritor' estaria exclusivamente implicado nas produções tidas como, digamos, ainda perfectíveis. O reescritor Carlos de Oliveira, e o cunho meta-reflexivo que imprime à sua obra, aproximam-na de ser algo semelhante a uma construção infinita, lenta, virtualmente nunca acabada, ou acabável, porque necessariamente re-feita pela acção de uma poética que retroactivamente olha e molda à sua luz as matérias primeiramente aparecidas e ainda rudimentarmente trabalhadas. Podemos também dizer que o movimento da reescrita, ao querer tornar a obra o mais fiel possível à condição misteriosa do real, quer também, incessantemente, construí-la a partir dos materiais e efeitos mais rudimentares e 'rarefeitos', uma vez que, estando minimamente saturados de significações, se encontram na proximidade das coisas primeiras, e assim podem igualmente ser o alicerce de algo que se situe precisamente no universo das coisas primeiras.

Estas reflexões podem fazer-nos situar a poética de Carlos de Oliveira, à semelhança do que faz Martelo, no espaço da modernidade estética, sobretudo pelo seu carácter metareflexivo, mas também pela concentração expressiva com que almeja construir o espaço poético, propriedade essa que porventura poderíamos aproximar até de um certo carácter fragmentário bastante frequente na modernidade (não tanto em Carlos de Oliveira), porque também o fragmento procura, em última análise, surpreender o fulgor da vida no fugaz instante em que ela reverbera e, assim, fixar a desmesura. 
Em jeito de síntese, e reportando-nos ao "Soneto" de Cantata, bem como ao "Soneto Fiel" de Sobre o Lado Esquerdo, surpreendemos na poética de Carlos de Oliveira, tal como CRUZ (1999b, p.70) parece assinalar, a procura de uma derradeira realidade através das palavras, as quais acabam por confundir-se com ela. O peso das palavras é excessivo, desmedido, porque, ao serem a representação, o símbolo, dessa realidade inalcançável, acabam elas próprias por converter-se nessa realidade, adquirindo-lhe a imensurável espessura. Mas esta espécie de desvio metonímico opera-se, quanto a nós, ao serviço de uma permanente conversão a essa derradeira realidade, ultimamente transcendente. É esta nova realidade de que se revestem as palavras que lhes confere o seu peso, a sua densidade, e por isso mesmo "levantar a torre do meu canto", i. e., construir na linguagem um espaço que dê testemunho desse seu carácter de linha tangencial de uma realidade outra, é sinónimo de "recriar o mundo pedra a pedra", processo em que a linguagem passa a merecer o centro das atenções para poder adquirir uma concentração tal que a faça ser precisamente transparência de outra coisa. Porém, ao contrário do que afirma CRUZ (1999a, p.46), não nos parece que a missão do poeta seja sobretudo "fixar [...] o movimento da realidade", mas antes abrir uma via para que o ser humano deixe invadir-se pelo movimento e a natureza da realidade derradeira, tão somente porque ela partilha com ele (ser humano) uma mesma condição misteriosa e, nessa qualidade, pode leválo a encontrar-se mais profundamente consigo mesmo, fazendo-se de algum modo, pela mediação da linguagem, espelho do próprio ser humano. É assim que às "palavras de ferro", num tempo futuro (tempo incerto de uma idealidade que é o testemunho de que a realização do ser humano terá de dar-se em patamares progressivamente mais elevados), será dada "a leve têmpera do vento".

\section{Uma leitura de Micropaisagem enquanto paradigma da rarefacção e do rigor poético na obra de Carlos de Oliveira}

O livro Micropaisagem é composto por oitenta e dois textos póeticos, agrupados em doze conjuntos de poemas: "Estalactite" (vinte e quatro textos); “Árvore" (oito textos); "Debaixo do Vulcão" (oito textos); "Fogo" (três textos); "Aresta" (cinco textos); "Vidro" (quatro textos); "Puzzle" (três textos); "Filtro" (quatro textos); "Rasto" (cinco textos); "Mapa" (dois textos); "Espaço" (dez textos); "Líquenes" (seis textos). Cada texto aproxima-se do soneto, na medida em que é composto por catorze versos e mantém uma forte concentração expressiva. Os versos são curtos, atingindo, em poucos casos, um número máximo de sete sílabas métricas. De acordo com GUSMÃO (1981, p.49), cada um dos textos que compõem os poemas 
está estreitamente ligado, em termos sintácticos e semânticos, ao texto seguinte, sendo o encavalgamento uma das principais estratégias usadas pelo autor para alcançar esse efeito.

Os poemas de Micropaisagem, se lhes quiséssemos fazer uma genealogia, encontrálos-íamos como que em preparação, pelo menos no que se refere à organização formal e à procura de contenção expressiva, nos livros Descida aos Infernos, Cantata e Sobre o Lado Esquerdo. No entanto, neste livro os poemas assumem fundamentalmente um carácter metapoético, i. e., de auto-representação e reflexão sobre o processo de construção poética. GUSMÃO (1981) sublinha o facto de neste livro a poesia de Carlos de Oliveira mergulhar, como nunca antes tinha feito, no processo de "construção e desenvolvimento dos poemas", colocando assim ênfase na realidade das palavras enquanto "matéria significante" e "instrumento de representação-criação-transformação" (GUSMÃO, 1981, p.50) do real. Repare-se no poder desta última fórmula que Gusmão usa para sintetizar a vocação desta poesia: representar o mundo e, em simultâneo, criá-lo (diríamos até recriá-lo, reinaugurá-lo), transformando-o. Assim se aproxima esta perspectiva do que anteriormente afirmávamos relativamente ao rigor poético e à rarefacção, que pensamos serem paradigmaticamente ilustrados pelos poemas de Micropaisagem, como características de uma arte de construção dos símbolos, representações, formas de aceder e exprimir um estado de não-conhecimento que, abrindo maximamente a pessoa ao acolhimento da alteridade, a devolve à sua condição de potencialidade pura para criar.

O carácter metapoético e meta-reflexivo da poesia de Micropaisagem é acompanhado por uma extraordinária a atenção dada às mais pequenas coisas do mundo externo, à sua vida secreta, uma vez que aí reside uma matéria que, por não fazer parte dos conteúdos habituais que servem de suporte à comunicação, tem o poder de transformar-se em símbolo plenamente eficaz e com máximo poder transformativo. Esse símbolo remete sempre para uma realidade outra, inacessível, desmedida, ao mesmo tempo que, nessa condição, se fixa no permanente deslumbramento que é existir imerso na percepção da condição misteriosa do real.

Acompanharemos agora o desenvolvimento dos poemas deste livro, tentando encontrar nalguns lugares algo como um processo identificável nas construções dos espaços semânticos que concretize e resuma o movimento dialéctico que procuramos conceptualizar para interpretarmos o fenómeno poético em geral: (1) percepção da radical limitação do conhecimento humano; (2) acesso progressivo ao que denominámos estado de não-conhecimento (estado de vazio e silêncio interior que se revela como uma via de criação de abertura para o acolhimento da alteridade, acompanhado da percepção viva da condição misteriosa do real); (3) exercício da arte de construção de símbolos (como forma de inscrição do ser humano na 
sua condição de potencialidade pura para criar e como forma suprema de exercício da sua liberdade).

No primeiro poema de Micropaisagem, intitulado "Estalactite" (OLIVEIRA, 2001a, pp.209-232), o mais longo e um dos mais significativos do livro, desce-se ao "[...] céu calcário / duma colina oca", espaço totalmente deslocado da experiência quotidiana. Deste céu calcário "hão-de cair [...] gotas / de água ou pedra" que acordarão "as ténues flores / nas corolas de cal". As "corolas de cal" são a realidade no seio da "colina oca", enquanto as flores são o que o sujeito poético ausculta como vida potencial no cenário em que se encontra, vida essa que deseja e que o inunda. Vemos que se dá também a entrada num outro tempo. Antecipa-se um futuro, "daqui a alguns milénios", quando o que hoje está petrificado mostrar a vida que nele agora apenas pelo poder da imaginação se deixa adivinhar. Essa vida, apesar do tempo que separa o sujeito poético da manifestação dela (“milénios”), está, contudo, muito próxima, tão próxima "que julgo ouvir, / filtrado pelo túnel / do tempo, da colina, / o orvalho num jardim". A vida potencial, situada no futuro, irradia desse futuro e vem inscrever-se no coração do presente, fecundando-o, ao ponto de transformá-lo e convertê-lo em si. Eis o movimento de transfiguração do presente a partir do que, estando deslocado desse presente, contém o que ao presente falta (neste caso, a vida, a frescura, a fluidez).

Depois deste momento inicial há uma centração nos processos mínimos do cenário dentro do qual o poema se desenvolve. Deparamo-nos, no entanto, com uma inversão da percepção temporal dos fenómenos. Situamo-nos numa “[...] memória / ao contrário", surpreendendo do fim para o princípio a queda de uma gota de orvalho: "o som do orvalho" que cai sobre as pétalas vem em primeiro lugar, depois "a lenta contracção / das pétalas”, antes de a gota de orvalho tocar nelas e as abrir, em seguida "o peso da água / a tal distância", quando a gota se encontra prestes a cair, e a síntese de tudo isto, "o ritmo da pedra / dissolvida / quando poisa / gota a gota / nas flores antecipadas.", ou seja, todo o processo da queda de uma gota de orvalho quando ainda não há flores e elas são apenas "flores antecipadas". Toda esta visão revertida, do futuro para o presente, concentra em si a virtualidade de recentrar a atenção naquilo que, por ser percebido de forma não habitual, recupera a sua densidade.

No terceiro texto de "Estalactite" encontramos como que o culminar deste movimento iniciado nos textos anteriores, sendo-nos revelado como o poema "acharia / o seu microrigor". Este 'micro-rigor' acontece quando o poema é capaz de debruçar-se sobre o processo que o desencadeia, "a própria oscilação / interior", entre tempos diversos do presente. É o poema a descer ao fundo de si mesmo, a regressar à sua origem e a centrar-se naquilo que contém de essencial: a promessa de vida que antecedeu a vida agora petrificada. Porque antes 
da água agora cristalizada havia água em estado líquido, livre, pronta para despertar "flores". O 'micro-rigor', em parte, consistirá numa assunção consciente por parte do poema da sua própria origem, situada numa vida plena. É um movimento do passado para o presente. A vida futura é, afinal, a restauração da vida passada, donde tudo dimana. Mas todo este movimento, visto no seu conjunto, diz ao presente o que o passado é, quando cotejado com o futuro: vida que promete mais vida, vida fecunda, vida que se propaga, se multiplica.

Deste modo, assistimos a um "[...] tempo, / que a linguagem / pôs / em vibração", sendo-nos sugerido ir até "onde a velocidade / se fractura / e aí / determinar / com exactidão / o foco / do silêncio". Este é o lugar em que com mais força nos deparamos com a condição misteriosa do real. Depois disto, "a cal”, matéria do presente aberta à manifestação de uma vida futura, pode "florir / nesta caligrafia / de pétalas / e letras.", reverberar na espessura simbólica do poema.

Mas nas palavras do poema nunca deixa de haver um limite: "O pulsar / das palavras, / [...] / lembra / o das estrelas / antes / de caírem.” O poema é um instante de fulguração, que tende para o "silêncio", e é como instante de fulguração que melhor dá a ver esse mesmo silêncio. $\mathrm{O}$ ponto mais alto deste movimento atinge-se porventura quando as palavras, depois de perdidas nesse "espaço / de tensões obscuras", são reavidas "num grau de pureza // extrema, / insuportável, / quando / o poema / atinge / tal / concentração / que transforma / a própria / lucidez / em energia / e explode / para sair / de si:", como a estrela que "rebenta" por ser "incapaz / de conter / a sua forma / logo / que a cintilação / a expande / um pouco / mais".

Em "Estalactite", paralelamente a vários movimentos de subida ao silêncio, que culminam em algo semelhante a uma "explosão", assistimos também ao recorrente retorno a um ponto em que o poema, depois de escrito, é apenas o rasto da irradiação da extraordinária energia que lhe deu origem. Cremos que isto é legível no último texto: "enquanto / a vagarosa / escultura do mundo, / a vaga rosa / modelando / as flores / adiadas na cal / escurece também / e o seu caule / esquivo / se desfaz / em som[bra] / apenas / por ser escrito."

A propósito deste último texto, podemos através dele ilustrar, comparando o seu final com o do texto IX, este movimento cíclico que, quanto a nós, percorre todo o poema. Assim, enquanto que no último texto, como vimos, "a vaga rosa / [...] o seu caule / esquivo / se desfaz / em som[bra] / apenas / por ser escrito.", no texto IX, ao invés, é-nos proposto "Imaginar / o som do orvalho, / [...] / e captá-lo como / se nascesse /apenas / por ser escrito." A escrita, por um lado, tem o efeito de reabilitar as coisas, no momento em que se encontra preenchida por um ímpeto vital, e, por outro lado, tem o efeito contrário, o de tornar-se opacidade delas, quando esse ímpeto vital se reduz e se desvanece. Ao leitor caberá a tarefa de receber a vida 
que o poema pretende captar, deixar-se invadir por ela, e a partir daí mergulhar numa visão da realidade renovada por meio da experiência poética.

Faremos agora uma breve incursão pelos poemas de Micropaisagem que se sucedem a "Estalactite". “Árvore” (OLIVEIRA, 2001a, pp.233-240) parece assentar sobre um adentramento na carga simbólica de um "baú" ao canto de um "quarto" (e do próprio quarto), onde se guardam as lembranças familiares. Há uma série de estratos, de planos temporais, que, ilustrando eloquentemente o processo que serve de base à construção de todos os poemas do livro, se sobrepõem ao longo do poema, em cada um dos quais é protagonista uma determinada parte de um ciclo: uma árvore cuja madeira é transformada em suportes que vão testemunhar uma história familiar e absorver a sua memória. Estes planos, em que tomam sucessivamente evidência diferentes regiões de espaço (raízes, árvore morta, baú, etc.), são intersectados, gerando-se um poderoso dinamismo entre cada um deles. Daqui deriva o intenso efeito poético produzido.

O texto "Debaixo do Vulcão" (OLIVEIRA, 2001a, pp.241-248) parece constituir uma espécie de testemunho da intensidade vital em que o sujeito poético está mergulhado. $\mathrm{O}$ "álcool" lê-se como uma espécie de forma de manter a atenção concentrada no que é mais importante - "a essência / recôndita / do álcool” é "ladrada" e "lavrada" pelo "[...] vulnerável cão / do espírito". Cada copo bebido é "sempre o último", o que é sintoma do poder da visão que se tem. Porque "existe ainda / o amor / e o vulnerável cão / do espírito / que lavra / cada palavra".

Em "Fogo" (OLIVEIRA, 2001a, pp.249-251), “O fósforo" que "acende o cigarro" é o ponto de partida para um desenvolvimento em que o sujeito poético, à semelhança de Orfeu, se entristece por Eurídice (figura do destinatário de toda a poesia?), lamentando-se porque o seu canto não vai além das sílabas que se despedaçam "entre as chamas / de um inferno / menor / que o fogo / deste fósforo."

“Aresta" (OLIVEIRA, 2001a, pp. 252-256) parte da situação em que alguém se encontra encarcerado. No lugar árido do cárcere, em que todos os limites parecem asfixiantes, nessa desolação e falta, aprende-se "como / se transforma / o espírito / em pedra preciosa, / endurecendo-o / pouco a pouco / [pedra / contra pedra]", criando a possibilidade de resistir à opressão, de parar a "compressão", "para impor / diante / do que pára / o trémulo / fulgor / da vida." O espírito é a fonte da vida, o único lugar em que a vida não se deixa diminuir. O espírito restitui à vida a sua reverberação, e nessa condição é necessário que se expanda.

Em "Vidro" (OLIVEIRA, 2001a, pp.257-260), viver nas mansardas aparece como símbolo de uma condição marginal que pode despertar para pequenos factos em que a vida é 
surpreendida no seu esplendor: "a) o orvalho / mais cedo,"; "b) a madrugada / só para si / alguns instantes / antes / da luz / [ou o vidro?] / se partir / nas camadas inferiores / do prédio"; “c) a chuva / mais perto / desse deserto / interior // de cada um;"; "d) o musgo, uma luva / que cinge / múltiplos dedos / argilosos,”; “e) fulgores minúsculos / que acendem / a sílica [...]”.

No poema "Puzzle" (OLIVEIRA, 2001a, pp.260-263), o sono entre dois amantes surge como metaforização da alienação, do desvio da vocação do amor e da sua fecundidade: “e assim / as peças / do puzzle / deslembradas / de entrar / umas / nas outras / transformam-se / em rios paralelos / correm / lado a lado / toda a noite / no mesmo leito / estéril."

"Filtro" (OLIVEIRA, 2001a, pp.264-267) põe-nos diante de uma situação em que alguém olha as chamas de uma lareira. Daí se desenvolve a ideia, totalmente demarcada da imagem inicial, de que "O poema / filtra / cada imagem / já destilada / pela distância, / deixa-a / mais límpida".

No cenário de "Rasto" (OLIVEIRA, 2001a, pp.268-272), alguém (a pessoa amada) entra no espaço onde o sujeito poético escreve, e, não podendo reconhecê-lo devido à luz forte do candeeiro junto dele, segue o seu caminho, desaparecendo, misturando-se com a falência do que é imaginado pelo próprio sujeito poético. Nada fica desse visitante senão o seu "rasto" na página onde se ensaia a escrita.

"Mapa" (OLIVEIRA, 2001a, pp.273-274) dá-nos a imagem do "poeta" (ou "cartógrafo") como alguém que desenha territórios áridos, esperando contudo que alguma "ave errante / traga / à solidão / do mapa," "um frémito, / um voo, / se for possível / voar / sobre tanta / aridez."

O poema "Espaço" (OLIVEIRA, 2001a, pp.275-284), retomando algum do universo de "Estalactite", parece desenvolver a imagem de alguém que é sacrificado, morto. A experiência da morte, experiência limite, surge como tendo o poder de centrar a existência no que é essencial, sublinhando-se a importância que a poesia pode ter aí: “mas / conheço 'a existência / na sociedade / de problemas / cuja solução / só pode imaginar-se / através / duma obra poética',". Contudo, a escrita tentada, de tão exígua, permanece precária e limitada para operar a mudança desejada, a revolução, dando inevitavelmente lugar ao "[...] silêncio / no livro."

Finalmente, vemos em "Líquenes" (OLIVEIRA, pp.285-290) a memória a regressar ao seu "[...] lugar / mais frio", "nítido / como um centímetro / quadrado [...]", "de neve e luz", “[...] paisagem / de líquenes", em que "o sono / criptogâmico" é "incapaz de sonhar / a forma duma flor". O quadro invocado é tão nítido que parece vir até de antes da infância, de uma “[...] infra-infância”. Mas há uma espécie de estagnação que se apodera dos elementos e se reproduz também no livro. E através dessa estagnação (regresso à mineralização da vida?) "se 
cumpre / o eclipse / gradual": "assim a luz e a neve / se ocultam / pouco a pouco, assim / se esquece." Aparece um lugar remoto no tempo subjectivo em que o rasto do tempo histórico, tempo da vida concreta, não pode chegar. A memória esvai-se, regressa-se a uma existência árida. $\mathrm{O}$ esquecimento prevalece; percebemos que a vibração de todo o percurso poético ensaiado em Micropaisagem é de tal modo intensa que não pode ter paralelo no mundo senão através de um fugaz clarão que sempre volta a ser silêncio.

De toda esta breve leitura nos fica a evidência de que no universo de Micropaisagem se assiste a uma decomposição do real nas suas partes mínimas, como se se quisesse chegar a uma parte indivisível, elementar. E este impulso de atenção ao mínimo é reproduzido pela estrutura formal e sintáctica dos textos. Olhamos para este itinerário poético descobrindo nele o desejo de captar algo de essencial, cuja descoberta exerça uma transformação radical sobre quem disso se aproxime. Mas o poder acumulado nessa estrutura elementar que se busca, e no seu dinamismo fecundativo, é tão desmedido que não pode, como dissemos já, durar mais que o instante de uma fulguração. Daí que o livro termine com a aparente vitória daquilo que precisamente se pretendia erradicar: o esquecimento, talvez a morte. Todavia, a prevalência destes lança-nos numa tensão ainda maior: a do desafio de reactualizar o mais possível o itinerário de uma escrita atenta a um mundo sem palavras, desmedido, outro, para que dele se escute o silêncio da vida surpreendida no sua mínima irradiação e esse silêncio se demore pelas coisas e produza mais vida. O 'micro-rigor', expressão que ocorre, como vimos, no poema "Estalactite", é, de facto, a que nos parece que mais agudamente define a vocação da poesia de $M i$ cropaisagem: a procura de, através do poema, captar a ressonância íntima daquilo que se situa para além das palavras. A escrita torna-se rarefeita para mais facilmente reproduzir a experiência de contacto com o indizível, para mais facilmente devolver ao leitor o lugar de nãoconhecimento onde tudo resplandece, assumindo a sua função mediadora entre o finito e o infinito, o sujeito e o que o transcende (e se torna fonte de criatividade).

Com a breve incursão que efectuámos nos poemas de Micropaisagem ficou também patente que a concretização deste 'micro-rigor' de que falamos, no seguimento da dialéctica que tentámos esboçar no sentido de lançar luz sobre o fenómeno poético [e que, relembramos, enunciámos do seguinte modo: (1) percepção da radical limitação do conhecimento humano; (2) acesso progressivo ao denominado estado de não-conhecimento (estado de vazio e silêncio interior que cria a abertura necessária para o acolhimento da alteridade, acompanhado da percepção viva da condição misteriosa do real); (3) exercício da arte de construção de símbolos (como forma de inscrição do ser humano na sua condição de potencialidade pura para 
criar e como forma suprema de exercício da sua liberdade)], é algo que opera simultaneamente nas fases (2) e (3) por nós identificadas.

Lancemo-nos primeiro sobre que mecanismos subjazem ao 'micro-rigor'. Como apontámos em "Estalactite", opera-se um movimento de saída dos espaços e tempos quotidianos, ou distorção desses espaços. A estes processos chamamos desespacialização e destemporalização. Não é que as categorias espaciais e temporais desapareçam, mas, num primeiro momento, são de tal modo diferentes, estranhas, que o impacto profundo que causam transmite a sensação de não haver tempo nem espaço. Estes processos podem também ser lidos como a mimetização do que ocorre em experiências de conhecimento por vias diversas das da experiência cognitiva habitual (estados alterados de consciência), e das quais a experiência mística constitui o paroxismo. Nestas experiências, tempo e espaço deixam de ser experimentados do mesmo modo (cf. SIMÕES, 2001, pp.3-13). Aceder-se-ia assim a algo próximo de um 'êxtase' - estar fora (ek-) do lugar habitual (stasis) (incluindo 'lugar' as categorias de tempo e de espaço). Ora, este tipo de experiências coincidiria precisamente com o acesso ao estado de não-conhecimento, em que se assistiria a uma tendencial identificação entre sujeito e objecto.

No que diz respeito à desespacialização, observa-se na poesia de Micropaisagem uma evidente deslocação da atenção para cenários de natureza e dimensionalidades diferentes daqueles que constituem o referencial espacial corrente (no caso deste livro, a atenção fixa-se tendencialmente no infinitesimal). Assim, põe-se diante do olhar o que é desmedido, por escapar aos padrões de referência comuns. Disto resulta um fenómeno de reespacialização, de imersão num espaço novo, em que o desmedido, o que habitualmente não tem palavras, por um momento pode ser escutado de novo no seu resplendor. Depois desta experiência, que não pode prolongar-se indefinidamente, verifica-se uma flexibilização do espaço, o que significa que o espaço quotidiano, depois de um olhar sobre o desmedido, é de novo percebido na sua densidade original, como coisa outra.

No que se refere à destemporalização, que decorre paralelamente às alterações na categoria espacial, o tempo parece tender para um não-tempo, um tempo a-histórico - no limite, para uma infinita concentração de agora. Ao serem desvelados espaços alternativos, põe-se a nu a estrutura mesma do real, i. e., a sua permanente disponibilidade para ser contemplado, recebido e transformado. O mesmo é dizer que a condição dos dados do mundo se manifesta também aqui em plenitude, pondo-se em evidência como estão abertos para uma 'construção', uma 'criação'. Esta criação só pode acontecer agora, sempre agora. O processo de destemporalização culmina com a contracção do fluido temporal em pontos de máxima densidade possível, lugares da experiência subjectiva em que passado, presente e futuro são experimentados 
como constituindo uma única e mesma realidade no 'agora'. E em Micropaisagem esta contracção do fluido temporal é particularmente evidente na intersecção de planos que constantemente se verifica. Dá-se depois o regresso a um novo tempo, uma retemporalização, em que o devir do ser humano é percebido sobretudo como possibilidade de uma constante reactualização da pura potencialidade para criar em 'novos agoras'.

Em síntese, o ser humano reconhece que na sua relação com o mundo há sempre algo de 'ficcional'. Vai então, para ser ele mesmo protagonista de si, agente da sua liberdade, assumir essa limitação, que lhe indica que é, acima de tudo, um criador, e transformá-la em expansão virtualmente interminável daquilo que é porventura o traço que mais radicalmente o define: o da potencialidade pura para criar.

A alteração sofrida pelas categorias espacial (desespacialização, reespacialização e flexibilização do espaço) e temporal (destemporalização, contracção do fluido temporal e retemporalização) ocorre, segundo a nossa perspectiva, nas fases (2) e (3) da dialéctica da experiência poética. Como vimos, a fase (2) corresponde ao acesso ao estado de nãoconhecimento, com a imersão na percepção da condição misteriosa do real. Nesta fase, as alterações espaciotemporais ocorrem em acto, são directamente vividas pelo poeta. Na fase (3), de exercício da arte de construção de símbolos (correspondendo às 'escritas' e 'leituras' do poema), as alterações espaciotemporais são vividas em potência, são alvo de uma rememoração, sendo experimentadas de forma indirecta. Este constitui o momento em que se tenta moldar a matéria verbal à semelhança dessa inscrição no estado de não-conhecimento, de modo a ser-lhe fiel e a facilitar naquele que lê o poema o acesso a esse mesmo estado.

Consideramos ainda que as fases (2) e (3), às quais se acede através do impulso vital da fase (1), podem ocorrer em simultâneo.

\section{Conclusão}

A concepção de poesia que expusemos, e da qual a poesia de Carlos de Oliveira, nomeadamente a de Micropaisagem, nos parece um exemplo particularmente eloquente, vai ao encontro de um entendimento do fenómeno poético na sua estreita conexão com a dimensão espiritual do ser humano. Eduardo Lourenço parece enquadrar-se também numa leitura da poesia a este nível, quando afirma que "A obra vale pela densidade de silêncio que nos impõe.” (LOURENÇO, 2003a, p.29), ou que “A Poesia é, pois, um absoluto de expressão, mas 
só o é por, e na medida em que o homem se dá conta através dela da ineliminável distância que o constitui" (LOURENÇO, 2003b, p.64).

Olhamos a poesia como um espaço de mediação entre a realidade quotidiana e a realidade do inominável, facilitando a integração desta última na primeira e promovendo a sua revitalização. A experiência poética significa para o ser humano um encontrar-se com as suas raízes, com a sua origem, com a sua verdadeira identidade: a de alguém que, na sua limitação fundamental, é chamado a ser criador de vida. A "distância” de que fala Eduardo Lourenço não será mais do que a douta ignorância que anteriormente referimos, nível de um sábio não saber no âmbito do qual a subjectividade percebe que não pode coincidir com os objectos, mas apenas construir sentidos que maximamente lhes restituam o carácter de diferença essencial que lhes subjaz.

Podemos, em jeito de síntese, afirmar que esta concepção da poesia interpreta o fenómeno poético como uma anapneuse, uma recuperação da respiração, movimento este de significado existencial. Apontamos também para uma dimensão anapneumática da poesia, para um respirar para o alto que se opera na escrita poética.

\section{Referências}

CRUZ, Gastão. O Peso das Palavras na Poesia de Carlos de Oliveira. In: . A Poesia Portuguesa Hoje. $2^{\text {a }}$ ed. Lisboa: Relógio D’Água, 1999a. pp.45-48.

Carlos de Oliveira: a Linguagem dos Artesãos. In: . A Poesia Portuguesa Hoje. $2^{a}$ ed. Lisboa: Relógio D’Água, 1999b. pp.70-72.

CUSA, Nicolau de. A Douta Ignorância. Lisboa: Fundação Calouste Gulbenkian, 2000.

GUSMÃO, Manuel. Apresentação Crítica da Poesia de Carlos de Oliveira. In: . (Org., apresentação crítica, selecção, notas e sugestões para análise literária). A Poesia de Carlos de Oliveira. Lisboa: Seara Nova / Editorial Comunicação, 1981. pp.23-86.

KANT, Immanuel. Crítica da Razão Pura. Lisboa: Fundação Calouste Gulbenkian, 2001.

LOURENÇO, Eduardo. Esfinge ou a poesia. In: Tempo e Poesia. Lisboa: Gradiva, 2003a. pp.27-32.

O irrealismo poético ou a poesia como mito. In: . Tempo e Poesia. Lisboa: Gradiva, 2003b. pp.57-66.

MARTELO, Rosa Maria. Retrato do artista enquanto reescritor. Relâmpago, n. ${ }^{\circ} 11$, pp.107120, 2002. 
OLIVEIRA, Carlos de. Trabalho Poético. Lisboa: Círculo de Leitores, 2001a.

O Aprendiz de Feiticeiro. Lisboa: Círculo de Leitores, 2001 b.

RUBIN, Gustavo. A poesia como trabalho - Carlos de Oliveira e a experiência da rarefacção. Vértice, II $^{\mathrm{a}}$ série, $^{\text {o }}{ }^{\text {38 }}$, pp.45-53, 1991.

SILVESTRE, Osvaldo. Introdução à Poesia de Carlos de Oliveira. In: OLIVEIRA, Carlos de. Trabalho Poético (Antologia). Braga: Angelus Novus, 1996. pp.21-103.

SIMÕES, Mário. A Experiência Mística: o Ponto de Vista do Psiquiatra. In: SIMÕES, Mário; RESENDE, Mário \& GONÇALVES, Sandra (Coords.). Psicologia da Consciência Pesquisa e Reflexão em Psicologia Transpessoal. Lisboa: Lidel, 2001. pp.3-13. 